\title{
La violencia en la pareja
}

\author{
Florentino Moreno Martín ${ }^{1}$
}

RESUMEN En el presente artículo se describen las variables que están relacionadas con las distintas formas de violencia en la pareja. Estas variables se han organizado en un modelo teórico que tiene en cuenta los factores culturales, las características sociodemográficas y familiares, las actitudes y otras variables definidas como inhibidores y facilitadores de la violencia en situaciones de conflicto. Se entrevistó a una muestra representativa de 10821 personas en las ocho ciudades del proyecto ACTIVA y se tuvieron en cuenta las respuestas de las 6184 que habian convivido en un enlace formal (matrimonio) o de unión no reglada o libre durante el año anterior a la entrevista. Los datos se obtuvieron a partir de las respuestas verbales a un cuestionario completado en el domicilio familiar de los entrevistados. Las variables que tuvieron una asociación clara con la violencia conyugal fueron: el nivel socioeconómico (a menos recursos, más violencia), el sexo (las mujeres tendían a maximizar la violencia y los varones a minimizarla, aunque el nivel de violencia fue similar), la edad (más violencia en los jóvenes), el estado civil (más violencia entre los no casados), la experiencia de malos tratos en la infancia (los más maltratados), el consumo excesivo de alcohol (los que se han embriagado), los que tenían actitudes de justificación de la violencia y los que tenían menos habilidades para enfrentarse a los conflictos. Los actos de violencia, que se dan de forma bidireccional en la pareja, tienen su origen en los procesos de socialización, tanto por la práctica de malos tratos, como por la transmisión de valores que se concretan en actitudes justificadoras de la violencia. El equilibrio de poder entre los miembros de la pareja, la modificación de las actitudes, la mejora de las habilidades para resolver conflictos y la reducción de los elementos estresantes pueden contribuir notablemente a reducir los niveles de violencia conyugal.

Existe una dificultad evidente a la hora de definir los límites epidemiológicos del problema de los malos tratos en la pareja. Una fuente de datos estadísticos es la de los informes oficiales sobre defunciones, denuncias y demandas $(1,2)$. Es razonable pensar que el nivel de violencia real es siempre superior al que se obtiene de estas fuentes. Si tomamos como referencia las respuestas de los entrevistados de

\footnotetext{
1 Universidad Complutense de Madrid, España. Dirección postal: Facultad de Psicología, Departamento de Psicología Social. 28223 Madrid, España. Teléfono: (34) 91.394.29.66; fax: (34) 91.394.31.89; correo electrónico 1): fmoreno@correo.cop.es, 2): pssoc12@emducms1.sis.ucm.es
}

ACTIVA a las preguntas sobre agresiones fuera del hogar, se observa que por término medio solo se denuncian $24,4 \%$ de las acciones. Si tan pocos entrevistados denuncian los actos de violencia en el ámbito público, es lógico pensar que el porcentaje de personas que denuncian la violencia conyugal sea mucho menor. Para los varones, reconocer que una mujer les ha golpeado puede suponer un deshonor. Las mujeres no suelen denunciar el maltrato en la primera ocasión que este se produce, sino tras una dilatada historia de agresiones $(3,4) \mathrm{y}$, lo que es más importante, cuando se da una serie de circunstancias que permite que la denuncia se convierta en la ex- pectativa real de una separación del agresor y de protección por parte de las autoridades (5).

La otra fuente habitual de obtención de datos sobre la violencia en la pareja es la encuesta domiciliaria, cuyos datos muestran una incidencia mucho mayor de la que se estima a partir de las denuncias policiales o a los servicios sociales. El estudio de Straus, Gelles y Steinmetz (6) sobre la violencia en familias de los Estados Unidos de América puso de manifiesto que en una de cada seis familias de ese país un cónyuge maltrataba físicamente al otro, algo que se constató de nuevo en una investigación similar realizada en 1985 (7). Diversos estu- 
dios internacionales reflejan que el problema se da en la mayor parte de las culturas $(8,9)$. Aunque las encuestas reflejen una incidencia tan alta de la violencia conyugal, conviene tener en cuenta que, por muy bien que se haga la entrevista, no es fácil que una persona reconozca ante un extraño que el individuo al que supuestamente se unió libremente por amor, la abofetea o golpea con objetos contundentes.

Como recientemente señalaba Heise (10), si el problema de la violencia conyugal pasó del comentario privado y la consulta psiquiátrica al del debate público, no fue gracias a los estudios sociológicos, sino por el empuje de las organizaciones femeninas, ya sea del movimiento feminista americano o europeo, que presionan por la igualdad de derechos (11); de las organizaciones sociales de mujeres latinoamericanas que a su lucha social contra regímenes dictatoriales unieron la denuncia de la propia opresión en el interior de los hogares (12); o de movimientos sociales contra los abusos sexuales en Asia (13). De este modo, identificada la violencia conyugal con el maltrato hacia la mujer, el asunto pasó de los foros de debate feminista a su encuadre como problema de salud y desarrollo. Las limitaciones que supone la violencia para la incorporación de la mujer a los programas de desarrollo (14), el impacto económico sobre el sistema de salud $(15,16)$ y la necesidad de abordar el problema de forma global, vinculándolo con elementos institucionales y políticos, han sido factores que han jugado a favor de que actualmente la violencia conyugal esté ocupando un lugar destacado en la agenda de salud pública de instituciones internacionales tales como la Organización Panamericana de la Salud y la mayor parte de los ministerios de salud de países latinoamericanos y europeos.

Aunque existen varios trabajos orientados a comparar investigaciones sobre la violencia en la pareja (17), la diversidad de métodos empleados supone un freno para el análisis de los factores comunes que pueden estar asociados con el maltrato conyugal. Los estudios llevados a cabo en el pro- yecto ACTIVA pretenden ser una contribución en este sentido.

En el presente estudio, al definir las variables que supuestamente influyen en la aparición de conductas violentas en la pareja, se acepta la naturaleza multicausal del fenómeno. Cualquier repaso de la literatura sobre las causas de la agresión conyugal arroja docenas de factores relacionados con la misma (3, 18-20). Aunque existen recientes estudios sobre elementos de caracterización psicológica de la persona que ejerce los malos tratos $(21,22)$, hay una importante corriente de intervención que otorga a los factores culturales y normativos un papel central en la explicación de la violencia conyugal (23-25), ya sea resaltando la importancia de la acción social y política como factor preventivo (26) o utilizando una visión sistémica que integre estos factores en el ámbito terapéutico de la atención a parejas con problemas de maltrato (27).

Con el fin de estructurar de forma lógica las múltiples variables que en la literatura científica se han relacionado con la violencia conyugal, en el presente estudio se elaboró un modelo teórico explicativo (figura 1) cuyos principios están inspirados en las teorías del aprendizaje social de Albert Bandura $(28,29)$.

Según este modelo de referencia, la cultura, a partir de unos valores determinados, fruto de la historia y de la interacción humana, determina unas normas de actuación, que pueden formalizarse o no en leyes o reglamentos, pero que siempre están vigiladas y sancionadas. Los valores normalizados son transmitidos por medio de los procesos de socialización primaria $y$ secundaria y suponen distintos modelos de comportamiento para diferentes tipos de actores en función de determinadas características de identificación estructural, personal o de relación familiar $(30,31)$. En sistemas sociales rígidos donde el componente normativo está determinado por códigos claramente expuestos y sistemas de sanción previsibles, es relativamente sencillo definir si un comportamiento (por ejemplo, que el marido golpee a la esposa) se adecua o no a la norma y de- terminar hasta qué punto esta se cumple o no. En sociedades como las latinoamericanas y europeas, donde el empleo de la violencia en el hogar está formal y legalmente castigado, la pervivencia de la violencia en el hogar se puede atribuir a desviaciones de la norma (por problemas psicopatológicos o de otro tipo) o a elementos normativos no formales que están firmemente instalados en las actitudes de los individuos. Sin negar la importancia que en determinadas ocasiones reviste el trastorno psíquico en las conductas agresivas, consideramos más adecuado averiguar qué variables se asocian con el uso de la violencia y, a partir de ellas, hacer inferencias sobre cuáles son los elementos socioculturales que las sustentan.

Como se puede observar en el modelo, los tres grupos de características de identificación que suponemos pueden influir en la violencia conyugal son los de carácter estructural (ciudad, clase social), los personales (edad, sexo) y los que derivan de las relaciones familiares. Entre los elementos de identificación estructural, la ciudad es una de las variables de identificación más importantes y el eje del estudio. Aunque es cada vez mayor el intercambio de valores y normas culturales, el vínculo que se forma al pertenecer a un mismo estado-nación es fundamental para entender las formas de actuación.

La condición socioeconómica o clase social, más que un elemento facilitador de la violencia, se entiende aquí como elemento que define conductas. En la mayor parte de los estudios empíricos se informa de la existencia de una relación directa entre pobreza y mayor incidencia de violencia familiar (17, 32-34). Algunas de las explicaciones que se han dado de estas diferencias van desde las condiciones de estrés ligadas a la pobreza al no poder disponer de los bienes ofrecidos permanentemente, es decir, la hipótesis de la frustración-agresión $(35,36)$, hasta interpretaciones ligadas a la dinámica de la lucha de clases (37).

El sexo y la edad son las características de identificación personal que se han estudiado más frecuentemente en 
FIGURA 1. Modelo teórico que explica la violencia en la pareja. Estudio Multicéntrico sobre Actitudes y Normas Culturales frente a la Violencia (ACTIVA), 1997

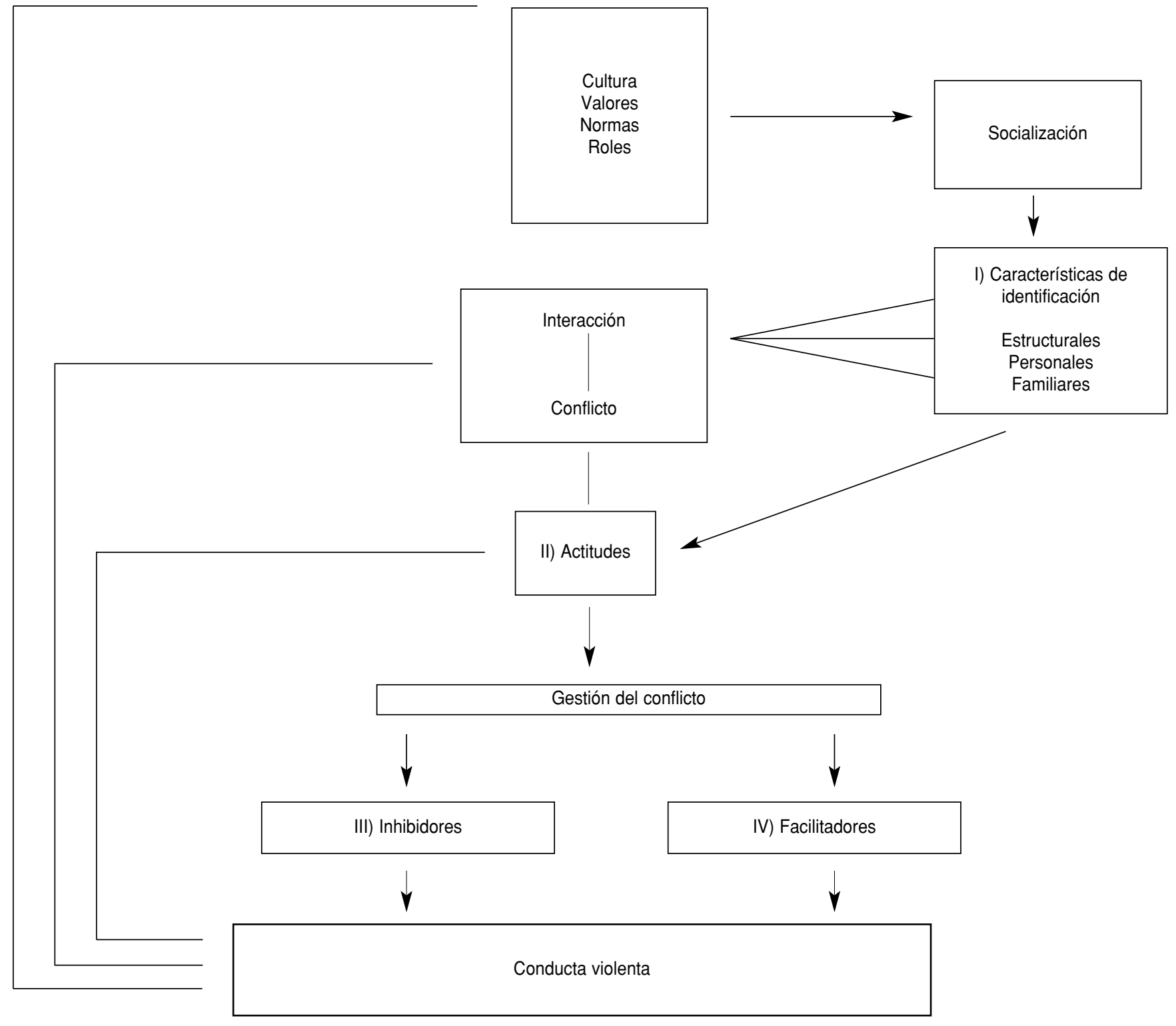

su relación con la violencia conyugal. La diferencia varón-mujer es el elemento central que determina la forma de comportarse en la pareja. La violencia conyugal tiende a asociarse con la violencia contra la mujer $(3,38)$. Son varios los estudios sobre la violencia en la pareja de carácter sociológico (39), clínico (27) y de trabajo social (40), en los que se afirma que la frecuencia con que los hombres y las mujeres ejercen las distintas formas de violencia es similar, aunque su resultado suele ser siempre más negativo para la mujer, debido fundamentalmente a la diferencia de fortaleza física. En los varones es más difícil observar los efectos de lo que Walker (41) denominó síndrome de la mujer maltratada (inhibición, aislamiento, fatalismo). Las consecuencias legales, sociales y psicológicas que deben soportar las mujeres maltratadas suelen ser más graves que las de los hombres $(3,4)$.

En un análisis llevado a cabo sobre las conclusiones de diversos estudios, Hotaling y Sugarman (17), al referirse a la edad, afirmaron que la violencia do- méstica era más frecuente cuando los miembros de la pareja, especialmente el agresor, eran jóvenes. A la misma conclusión se ha llegado en algunas investigaciones realizadas en madres adolescentes (42). Algunos estudios longitudinales (43) y transversales sobre mujeres maltratadas (2) confirman que los malos tratos suelen darse al comienzo de la vida en común (incluso en la fase del noviazgo).

El estado civil, la estructura familiar, la existencia de hijos y las diferencias entre los cónyuges (de edad, nivel aca- 
démico y trabajo) han sido estudiados también en su relación con la violencia en la pareja. En algunas investigaciones como las de Straus y Gelles (7) se partía de la hipótesis de que la vieja tradición medieval que otorgaba a los maridos el derecho a castigar a la esposa podía seguir vigente como norma cultural; sin embargo, cuando se estudiaron los distintos estados civiles, comparando el vínculo matrimonial con el de las uniones libres, comprobaron que la probabilidad de propinar malos tratos era mayor en estas últimas. Esta diferencia se atribuyó al mayor compromiso que supone la unión formal y los esfuerzos por mantenerla.

Hay dos visiones opuestas sobre el papel que la presencia de hijos $u$ otros miembros de la familia desempeña en los malos tratos entre los cónyuges. La primera supone que los hijos producen un efecto de normalización familiar que reduce la posibilidad de malos tratos; la segunda, que la presencia de hijos y de otros miembros de la familia (suegros, sobrinos, etc.) es un elemento de estrés añadido que favorece la violencia conyugal (44).

Las diferencias entre los cónyuges, las dificultades para la comunicación, el desequilibrio del poder o las dificultades en el desempeño de papeles son elementos básicos de conflicto en las parejas y fuente de posibles reacciones violentas $(45,46)$. Las diferencias de edad, origen social y nivel académico, económico o profesional entre los miembros de la pareja podrían generar disputas debidas a las diferentes formas de entender las relaciones $\mathrm{o}$, por el contrario, ser fuente de complementariedad y prevención del conflicto. Sin embargo, las verdaderas fuentes de conflicto son las interacciones violentas y el ciclo fatídico de reacciones emocionales que generan (maltratoarrepentimiento-reconciliación-maltrato). Las consecuencias de estas relaciones anormales se han estudiado desde la perspectiva clínica y legal y se han elaborado propuestas orientadas a las mujeres maltratadas (47), a los que ejercen el maltrato (48) o a los procesos de interacción entre los miembros de la pareja (27). También se han formulado críticas fundadas sobre las posibilida- des de usar procedimientos basados en los individuos (terapia de pareja) para resolver problemas institucionales de mayor envergadura $(49,50)$.

Se considera que las actitudes actúan como elementos mediadores entre las situaciones de conflicto y la forma de gestionarlo. En el caso de que los procesos de socialización se desarrollen adecuadamente, combinando lo emocional con lo cognitivo, las normas culturales son interiorizadas por los individuos que asumen como propios los papeles marcados por la cultura en función de las características de identificación de cada sujeto. Si una institución está suficientemente asentada en el sistema social, tendrá una incidencia directa sobre las actitudes de las personas de forma que sepan cómo actuar y por qué, y tengan sensaciones de placer o desagrado que les empujen a actuar en una $u$ otra dirección (componentes cognitivo, emocional y volitivo).

Si bien la interacción humana, especialmente la conyugal, genera situaciones de conflicto en las que precisamos de las actitudes para orientar nuestra conducta, en esta investigación solo se ha indagado sobre algunos elementos actitudinales (concretamente la justificación de la violencia relacionada con la vida conyugal), que se suponía que estaban directamente relacionados con una mayor o menor incidencia de la violencia y reflejaban algunas de las normas culturales mencionadas anteriormente. En otros estudios se afirma que algunos elementos actitudinales, como la justificación, la adaptación funcional, la tolerancia a la agresión, la empatía hacia el agresor, son básicos para que el maltrato se mantenga (24, 51,52 ).

Las normas culturales son elementos básicos para entender la violencia conyugal; los mismos tipos de individuos actúan de forma diferente ante situaciones aparentemente iguales. Existen importantes factores que facilitan o dificultan la acción violenta. Como elementos inhibidores de la conducta violenta, o recursos para hacerle frente, se han mencionado la capacidad para tener una percepción realista del estrés que se sufre (53), en- frentar situaciones de tensión y manejar habilidades de relación interpersonal, como el sentido del humor o la capacidad de empatía. Entre los elementos facilitadores de la agresión conyugal, se coincide en señalar como elementos esenciales el haber sufrido violencia en la infancia $(7,19,54,55)$; el consumo excesivo de alcohol $(7,21$, 56), las condiciones de carencia y pobreza; la presencia de armas y todos aquellos elementos que pueden incrementar las situaciones estresantes como el calor, el ruido, la contaminación, etc. $(18,57)$.

La forma violenta de resolver las situaciones de conflicto tiene una repercusión directa sobre todos los elementos explicados anteriormente: refuerza las actitudes justificadoras de la agresión, incrementa las posibilidades de nuevos conflictos y, cuando se articula en la movilización de grupos activos, modifica el marco normativo y el sistema de roles. Modelos de conducta personal innovadores, la acción comunitaria, determinadas modificaciones de la legislación y otras acciones públicas actúan sobre los valores, normas y roles en un proceso constante. No se debería hablar, por tanto, de elementos definitivos e inamovibles, sino de procesos históricos basados en la interacción humana.

Los objetivos básicos de la presente investigación son, primero, realizar un análisis descriptivo y comparativo del fenómeno de la violencia de pareja en las ocho ciudades en que se ha realizado el estudio y, segundo, averiguar qué variables están relacionadas con una mayor o menor incidencia de violencia conyugal en la muestra estudiada, tomando como referencia el modelo teórico explicado.

\section{MATERIALES Y MÉTODOS}

El universo de estudio del proyecto ACTIVA estuvo constituido por la población de 18 a 70 años de las ciudades participantes: Salvador de Bahía y Rio de Janeiro, Brasil; Santiago, Chile; Cali, Colombia; San José, Costa Rica; San Salvador, El Salvador; Caracas, Venezuela, y Madrid, España. En todas las 
CUADRO 1. Características de la submuestra de violencia en la pareja por ciudades. Estudio Multicéntrico sobre Actitudes y Normas Culturales frente a la Violencia (ACTIVA), 1997

\begin{tabular}{|c|c|c|c|c|c|c|c|c|c|}
\hline & $\begin{array}{l}\text { Salvador, } \\
\text { Bahía }\end{array}$ & Cali & Caracas & Madrid & $\begin{array}{l}\text { Rio de } \\
\text { Janeiro }\end{array}$ & $\begin{array}{l}\text { San } \\
\text { José }\end{array}$ & $\begin{array}{c}\text { San } \\
\text { Salvador }\end{array}$ & Santiago & Total \\
\hline \multicolumn{10}{|l|}{ Tamaño de la muestra } \\
\hline$\%$ sobre el total de ACTIVA & 48,5 & 55,9 & 52,4 & 56,0 & 62,5 & 57,8 & 62,2 & 64,4 & 57,1 \\
\hline \multicolumn{10}{|l|}{ Sexo $(\%)$} \\
\hline Varones & 52,0 & 48,5 & 36,0 & 37,0 & 46,7 & 42,0 & 49,1 & 46,6 & 45,3 \\
\hline \multicolumn{10}{|l|}{ Estado civila (\%) } \\
\hline Soltero/a & 1,2 & $\ldots$ & 0,9 & 2,3 & 1,7 & 0,6 & 0,6 & 0,7 & 0,9 \\
\hline Casado/a & 68,7 & 51,8 & 78,2 & 92,9 & 77,4 & 88,4 & 66,5 & 91,2 & 74,3 \\
\hline Unión libre & 29,8 & 48,2 & 20,6 & 4,2 & 18,8 & 10,7 & 32,5 & 7,8 & 24,4 \\
\hline Separado/a-Divorciado/a & 0,3 & $\ldots$ & 0,3 & 0,5 & 1,3 & 0,3 & 0,2 & 0,1 & 0,3 \\
\hline Viudo/a & $\ldots$ & $\ldots$ & $\ldots$ & 0,2 & 0,7 & $\ldots$ & 0,1 & 0,3 & 0,1 \\
\hline
\end{tabular}

${ }^{a}$ A pesar de estar conviviendo con otra persona (casados o en unión libre), algunos entrevistados definieron su estado civil como soltero o como el que mantenían respecto de su vínculo anterior (separado y viudo).

ciudades se estratificó tomando como base la condición socioeconómica (baja, media y alta) de los distintos sectores o secciones de las ciudades. Los métodos utilizados en dicho proyecto se detallan en otro artículo (58).

Para el análisis de la violencia en la pareja se extrajo de la muestra general (10 821 entrevistados) una submuestra de los que "viven en pareja". El vivir en pareja se definió según los siguientes criterios: 1) la persona ha estado casada o viviendo en pareja de hecho o en unión libre en alguna ocasión, 2) la persona considerada como pareja (ya sea cónyuge legal, compañero, amante o cualquier definición que se le quiera dar) vive actualmente con el entrevistado, y 3) el entrevistado contesta a alguna de las seis preguntas de violencia en la pareja. De los 10821 entrevistados, $6184(57,1 \%)$ reunieron los requisitos anteriores. En el cuadro 1 se describen las características de las personas seleccionadas (edad, sexo y estado civil) de la submuestra utilizada en el presente estudio.

El cuestionario utilizado para recolectar los datos fue el acordado en el proyecto ACTIVA. La variable dependiente de este estudio fue la violencia en la pareja, que se evaluó mediante seis preguntas, tres de agresión y tres de victimización. Se preguntó la frecuencia con que la persona gritó con rabia, dio una bofetada y pegó con un objeto que pudo haber lastimado a la pareja, y la frecuencia con que fue víctima de estas mismas conductas. El período evaluado para la agresión contra la pareja fue el año anterior a la realización de la encuesta. Las opciones de respuesta eran: "nunca/ninguna vez en el último año", "rara vez (1-2 veces)", "a veces (3-5 veces)", y "a menudo (6 veces o más)".

Como variables independientes se tomaron las planteadas en el modelo: las de identificación, las actitudes, los inhibidores y los facilitadores de la violencia. Las variables de identificación de la persona incluyeron nivel socioeconómico, hacinamiento (no hacinados: duermen dos o menos personas en cada cuarto; hacinados: duermen tres o más personas en cada cuarto), sexo, edad, estado civil, presencia de hijos, estructura familiar (convivencia con otros parientes y no parientes), diferencias de edad en la pareja (varón [V] > mujer [M] 10 o más años; $\mathrm{V}>\mathrm{M}$ 4 a 9 años; $\mathrm{V}=\mathrm{M} \pm 3$ años; $\mathrm{M}>\mathrm{V} 4$ a 9 años; M > V 10 o más años), diferencias de nivel académico en la pareja ( $\mathrm{V}>\mathrm{M} 2$ o más niveles; $\mathrm{V}>\mathrm{M} 1$ nivel; $\mathrm{V}=\mathrm{M} ; \mathrm{M}>\mathrm{V} 1$ nivel; $\mathrm{M}>\mathrm{V} 2$ o más niveles), y diferencias en el trabajo de la pareja (trabaja solo el varón; trabajan varón y mujer; no trabaja ninguno; trabaja solo la mujer).

Además, se evaluaron dos actitudes de justificación de la violencia. La primera, la justificación de la violencia en la pareja, se evaluó por el valor medio de las respuestas a dos preguntas ("Existen situaciones en las cuales se justifica que un hombre dé una cachetada a la esposa" y "Existen situaciones en las cuales se justifica que una mujer dé una cachetada al esposo"). La segunda, intolerancia social, se evaluó con arreglo al valor medio de las respuestas a cinco preguntas ("Sería conveniente que un barrio estuviera compuesto por personas: de una misma clase social, . . . de una misma religión, . . . de un mismo origen étnico o raza, . . . con las mismas ideas políticas" y "Me parece bien que la gente pueda echar de su barrio a ciertos grupos de personas"). Las respuestas, categorizadas en una escala de tipo Likert de cinco categorías, variaron entre "muy de acuerdo" y "muy en desacuerdo".

Como factor inhibidor de la conducta violenta se evaluó la habilidad para resolver pacíficamente los conflictos, a partir del valor medio de las res- 
puestas a tres preguntas ("Ante un problema, yo sé cómo controlarme para no pelear", "Si me insultan puedo perder el control y pelear" [los valores fueron invertidos], y "Ante un conflicto o desacuerdo serio con mi pareja puedo explicar mis razones sin enojarme"). Las respuestas, también categorizadas en una escala de cinco categorías, variaron entre "siempre" y "nunca".

Por otro lado, se evaluó el efecto de tres factores que facilitan la conducta violenta: la frecuencia de embriaguez durante el mes anterior a la encuesta, el haber sido castigado con golpes durante la infancia, y la tenencia de armas de fuego.

Para cada ciudad se calculó primero el porcentaje de personas que agredieron a la pareja o que fueron víctimas de agresión al menos una vez durante el año anterior a la encuesta. Segundo, solo entre aquellos entrevistados que notificaron violencia familiar, se calculó la media del número de veces que agredieron a la pareja o que fueron víctimas de agresión. Para calcular esta media, se asignaron los valores máximos de cada intervalo (0, 2, 5 y 12 veces). Al no haber un límite superior para la respuesta "a menudo", se optó por establecer el valor de 12 veces al año.

Con el fin de resumir la intensidad de la violencia, se construyeron dos variables ponderadas: violencia ejercida y sufrida. En estas nuevas variables se tuvo en cuenta la frecuencia de la conducta violenta y se asignó un peso mayor a las acciones de violencia más graves (golpear con objeto más que bofetada y esta más que gritar con rabia). El criterio de ponderación seguido fue tomar como conducta básica (con valor igual a 1) la más frecuente (gritar) y dar a las otras dos conductas un peso inversamente proporcional a la frecuencia de su aparición en el conjunto de la muestra. De este modo, una bofetada y un golpe con objeto tienen, respectivamente, 10 y 20 veces más peso que un grito. Por lo tanto, el valor final de esta variable ponderada se calculó con la siguiente fórmula:

Frecuencia del grito $\times 1+$ frecuencia de la bofetada $\times 10+$ frecuencia del golpe $\times 20$
Así, los valores de estas variables ponderadas podían variar entre $0 \mathrm{y}$ $372(12 \times 1+12 \times 10+12 \times 20)$. Además de esta frecuencia ponderada total, se calculó la frecuencia ponderada entre aquellos que ejercieron o que fueron víctimas de violencia.

Para validar el modelo se analizó la relación entre cada una de las variables mencionadas en párrafos anteriores (de identificación personal, actitudes, facilitadores e inhibidores) y las ocho variables de violencia en la pareja (las seis básicas y las dos ponderadas). Los criterios para determinar la significación estadística de las diferencias entre los valores de la variable independiente en función de los valores de violencia, así como el sentido y orientación de la asociación entre variables, fueron los siguientes:

1. Variables nominales versus las seis variables básicas: se emplearon tablas de contingencia y se calculó el estadístico ji-cuadrado para contraste de hipótesis y el estadístico $V$ de Cramer para el análisis de la asociación entre variables.

2. Variables ordinales versus las seis variables básicas: también se utilizaron tablas de contingencia y se calculó el estadístico ji-cuadrado para contraste de hipótesis y el estadístico $D$ de Somers para análisis de la asociación entre variables, considerando como dependientes las relativas a la violencia.

3. Variables dicotómicas (por ejemplo, el sexo) versus las dos escalas con valores de violencia acumulada y ponderada: en este caso se aplicó la prueba $t$ de Student para muestras independientes.

4. Variables con tres o más valores (tomadas una a una) versus las dos escalas con valores de violencia acumulada y ponderada: en este caso se realizó un análisis de la varianza con un factor, cuya significación estadística se calculó mediante el estadístico $F$. El nivel de significación estadística (alfa) se fijó como menor de 0,05 .

5. Dos o más variables independientes versus las dos escalas con valores de violencia acumulada y ponderada: en este caso se llevó a cabo un análisis factorial de la varianza. La significación estadística se calculó por medio del estadístico $F$ y como nivel de significación se aceptaron los valores $P$ menores de 0,05 . Estos análisis se realizaron considerando el sexo como uno de los factores.

Los resultados del análisis comparado fueron estudiados detalladamente con el fin de no aceptar como relevantes diferencias o asociaciones entre variables que, a pesar de parecer significativas desde el punto de vista del análisis estadístico, fueran el resultado de comparar grupos con un número de entrevistados extremadamente pequeño. Al tratarse de un estudio con ocho muestras diferentes, cada una de las ciudades presenta características propias en cuanto a los factores directa y significativamente relacionados con la violencia en la pareja. Ante la imposibilidad de presentar las múltiples posibilidades particulares, se decidió tener en cuenta como resultados relevantes los siguientes:

1. Variables que en la muestra total estuvieran asociadas (con resultados estadísticamente significativos) con alguna de las ocho variables de violencia. En estos casos se estudiaron las tablas de contingencia y los análisis de varianza de cada una de las ciudades. Si en al menos seis de las ciudades la tendencia de respuesta era la misma que en los datos generales, la variable se tuvo en cuenta, tomando nota de la excepción o excepciones. Los datos acumulados no son, por tanto, valores de una supuesta muestra representativa de las ciudades de América y España, para lo cual sería preciso haber realizado un diseño muestral conjunto o ponderar el peso de las submuestras en función del tamaño de los universos respectivos. Lo que se buscaba con los datos acumulados era analizar la similitud de las ciudades en las distintas formas de variabilidad. Por esta razón, se analizaron los datos globales y los de cada una de las ciudades y solo se tuvieron en cuenta cuando en un mínimo de 
seis ciudades se mantuvo la misma tendencia de respuesta.

2. Variables que en la muestra total no mostraban asociación significativa con la violencia en la pareja. En este caso se estudiaban los datos de las submuestras y se tenía en cuenta la variable solo si había dos o más ciudades con diferencias estadísticamente significativas, lo cual se consignó como tendencia específica de estas ciudades.

\section{RESULTADOS}

Como se aprecia en el cuadro 2, las ciudades se ordenaron de mayor a menor violencia ejercida, tomando como referencia la frecuencia ponderada total, del siguiente modo: Salvador de Bahía, Cali, San Salvador, Santiago, Caracas, Rio de Janeiro, Madrid y San José. Comparando la significación de las diferencias, las ciudades se pueden dividir en tres grupos en función del nivel de violencia y de las diferencias entre cada grupo: mayor violencia (Salvador de Bahía y Cali), menor violencia (San José y Madrid) y valores intermedios (las restantes).

En Caracas y Madrid es donde el porcentaje de personas que gritaron con rabia en alguna ocasión fue más alto; sin embargo, por la frecuencia con que se desarrolla esta conducta, las dos ciudades brasileñas fueron las de mayor incidencia de gritos en la pareja. Juntando los datos de las ocho ciudades, fue 10 veces más frecuente gritar que abofetear y dos veces más frecuente abofetear que pegar con un objeto. Esta proporción media se constató fundamentalmente en las ciudades con una violencia intermedia, mientras que en San José y Madrid la proporción fue menor y en Salvador de Bahía y Cali, mayor. En esta última ciudad fue casi tan habitual golpear con un objeto que dar bofetadas. En relación con la violencia física, se observó que en Salvador de Bahía era más frecuente la bofetada y en Cali, el maltrato con objetos.

CUADRO 2. Frecuencia de la violencia ejercida y recibida en la pareja por ciudad. Estudio Multicéntrico sobre Actitudes y Normas Culturales frente a la Violencia (ACTIVA), 1997

\begin{tabular}{|c|c|c|c|c|c|c|c|c|c|}
\hline & $\begin{array}{c}\text { Salvador, } \\
\text { Bahía } \\
(n=671)\end{array}$ & $\begin{array}{c}\text { Cali } \\
(n=1281)\end{array}$ & $\begin{array}{c}\text { San } \\
\text { Salvador } \\
(n=802)\end{array}$ & $\begin{array}{l}\text { Santiago } \\
(n=781)\end{array}$ & $\begin{array}{c}\text { Caracas } \\
(n=680)\end{array}$ & $\begin{array}{c}\text { Rio de } \\
\text { Janeiro } \\
(n=696)\end{array}$ & $\begin{array}{c}\text { Madrid } \\
(n=619)\end{array}$ & $\begin{array}{c}\text { San } \\
\text { José } \\
(n=654)\end{array}$ & $\begin{array}{c}\text { Total } \\
(n=6184)\end{array}$ \\
\hline Una o más veces (\%) & 64,4 & 61,4 & 52,4 & 64,2 & 65,3 & 60,1 & 64,9 & 42,5 & 59,6 \\
\hline Media $^{\mathrm{a}}$ & 5,3 & 4,6 & 4,3 & 4,6 & 4,5 & 5,1 & 4,4 & 4,1 & 4,6 \\
\hline \multicolumn{10}{|l|}{ Dio golpe } \\
\hline Una o más veces (\%) & 4,2 & 6,6 & 3,0 & 2,0 & 1,9 & 1,3 & 0,0 & 0,9 & 2,9 \\
\hline Media $^{a}$ & 4,0 & 3,3 & 3,3 & 3,1 & 4,0 & 3,1 & 0,0 & 2,5 & 3,4 \\
\hline \multicolumn{10}{|l|}{ Violencia sufrida } \\
\hline \multicolumn{10}{|l|}{ Le gritaron } \\
\hline Media $^{a}$ & 3,1 & 3,3 & 4,1 & 3,3 & 3,7 & 4,0 & 3,6 & 3,3 & 3,5 \\
\hline \multicolumn{10}{|l|}{ Le golpearon } \\
\hline Una o más veces (\%) & 3,6 & 5,3 & 3,2 & 1,8 & 1,5 & 1,3 & 0,8 & 1,2 & 2,7 \\
\hline Media $^{a}$ & 3,5 & 3,3 & 4,1 & 2,2 & 3,6 & 5,2 & 3,2 & 3,1 & 3,5 \\
\hline \multicolumn{10}{|l|}{ Escalas ponderadas } \\
\hline \multicolumn{10}{|l|}{ Violencia ejercida } \\
\hline Algún acto violento (\%) & 64,7 & 63,2 & 53,4 & 64,3 & 65,4 & 60,3 & 65,2 & 43,0 & 60,2 \\
\hline Frecuencia ponderada (Sí) ${ }^{b}$ & 15,2 & 14,7 & 11,6 & 9,4 & 9,0 & 9,6 & 5,3 & 6,7 & 10,8 \\
\hline Frecuencia ponderada $\left(\right.$ Total) ${ }^{c}$ & 9,8 & 9,3 & 6,2 & 6,0 & 5,9 & 5,8 & 3,5 & 2,9 & 6,5 \\
\hline \multicolumn{10}{|l|}{ Violencia sufrida } \\
\hline Algún acto violento (\%) & 61,1 & 53,5 & 48,8 & 57,1 & 56,8 & 57,1 & 58,3 & 37,7 & 53,7 \\
\hline
\end{tabular}

a Media: frecuencia media anual con la que ejercen esta conducta las personas que alguna vez la han realizado.

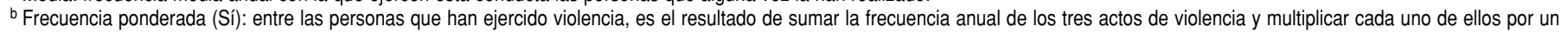

índice que refleje su gravedad (el valor inverso de su frecuencia de aparición en la muestra). El peso de cada acto de violencia es: grito $=1$, bofetada $=10$ y golpe $=20$.

${ }^{c}$ Frecuencia ponderada (Total): lo mismo que en el caso anterior, haciendo el cálculo sobre todas las personas (hayan ejercido o no la violencia). 
CUADRO 3. Características sociodemográficas versus violencia ejercida en la pareja. Estudio Multicéntrico sobre Actitudes y Normas Culturales frente a la Violencia (ACTIVA), 1997

\begin{tabular}{|c|c|c|c|c|c|c|c|c|c|}
\hline & \multirow{2}{*}{\multicolumn{2}{|c|}{ Gritó }} & \multirow{2}{*}{\multicolumn{2}{|c|}{ Dio bofetada }} & \multirow{2}{*}{\multicolumn{2}{|c|}{ Dio golpe }} & \multicolumn{3}{|c|}{ Violencia ejercida (global) } \\
\hline & & & & & & & $\%$ & \multicolumn{2}{|c|}{$\begin{array}{l}\text { Frecuencia } \\
\text { ponderada }\end{array}$} \\
\hline \multicolumn{10}{|c|}{ Condición socioeconómica } \\
\hline Alta & 51,7 & 4,3 & 1,5 & 2,6 & 1,4 & 4,1 & 52,2 & 7,2 & 3,8 \\
\hline Media & 57,9 & 4,4 & 4,1 & 2,9 & 2,0 & 3,0 & 58,6 & 8,4 & 4,9 \\
\hline No hacinado & 57,9 & 4,5 & 4,5 & 3,1 & 2,4 & 3,3 & 58,5 & 9,5 & 5,6 \\
\hline Hacinado & 66,4 & 5,3 & 10,0 & 3,3 & 5,6 & 3,6 & 67,1 & 16,1 & 10,8 \\
\hline \multicolumn{10}{|l|}{ Sexo } \\
\hline Masculino & 57,6 & 4,3 & 5,2 & 2,8 & 2,7 & 3,0 & 58,3 & 9,4 & 5,5 \\
\hline Femenino & 61,3 & 4,9 & 5,7 & 3,5 & 3,1 & 3,7 & 61,8 & 11,9 & 7,4 \\
\hline $57-70$ & 46,6 & 4,2 & 1,7 & 2,2 & 1,1 & 3,2 & 47,3 & 6,4 & 3,0 \\
\hline \multicolumn{10}{|l|}{ Estado civil } \\
\hline Casado & 56,4 & 4,4 & 4,0 & 3,1 & 1,7 & 3,2 & 2,6 & 8,5 & 4,8 \\
\hline No casado & 68,8 & 5,3 & 9,7 & 3,3 & 6,3 & 3,6 & 6,1 & 16,3 & 11,4 \\
\hline \multicolumn{10}{|l|}{ Hijos } \\
\hline Sí & 62,6 & 4,7 & 5,8 & 3,2 & 3,3 & 3,4 & 3,8 & 11,2 & 7,1 \\
\hline No & 54,6 & 4,4 & 4,9 & 3,2 & 2,3 & 3,4 & 3,0 & 10,1 & 5,6 \\
\hline
\end{tabular}

Al comparar las conductas de ejercer la violencia frente a sufrirla, en la muestra global hubo coincidencia entre ambas en $73,8 \%$ de los casos en proferir gritos, en $95,3 \%$ en abofetear y en $97,2 \%$ en golpear con un objeto. Respecto a estas últimas dos variables, no se observaron diferencias estadísticamente significativas entre los que dan más de lo que reciben y los que reciben más de lo que dan. Sí se observaron diferencias entre las variables gritar-ser gritado. En todas las ciudades el porcentaje de personas que gritó fue superior al que dijo haber sido gritado.

En los diversos cuadros de este artículo se describen las asociaciones, que resultaron significativas estadísticamente, entre las variables independientes del modelo y la violencia. Las variables de identificación de la persona, con sus tres grupos - estructural (nivel socioeconómico y hacinamiento), personal (sexo y edad) y familiar (es- tado civil y presencia de hijos) - se presentan en el cuadro 3, detallando las diferencias en función del sexo en los cuadros 4 y 5. Después, en el cuadro 6 , se describen las asociaciones entre violencia y tres elementos más del modelo teórico: las actitudes de justificación de la violencia (violencia con la pareja, intolerancia social), un factor inhibidor de la violencia (habilidad para resolver conflictos pacíficamente), y factores facilitadores de la violencia (embriaguez, haber sido golpeado durante la infancia y portar armas de fuego).

En las tres formas de conducta violenta se observó que, a mayor nivel socioeconómico, menor era el nivel de violencia $(P<0,001$, para gritos y bofetadas; $P=0,00016$, para golpes). Las ciudades que no siguieron la tendencia general fueron Cali (golpes), Rio de Janeiro (gritos), San José (bofetadas). En estas tres ciudades la distribución de frecuencias fue diferente de la del resto, aunque las diferencias no fueron estadísticamente significativas. En otras palabras, en la escala global de la violencia ejercida en estas ciudades se siguió manteniendo la tendencia general según la cual a medida que aumenta el nivel socioeconómico, menor es la violencia ejercida. San Salvador fue la única ciudad donde no se observaron diferencias significativas por nivel socioeconómico en ninguna de las tres formas de violencia (golpes, bofetadas y gritos) ni en la escala ponderada. Además, se observó una relación estadísticamente significativa entre hacinamiento y violencia $(P<0,001$ para todas las conductas) en todas las ciudades, excepto en Madrid (donde no se pudo hacer esta comparación al ser el grupo de hacinados extremadamente pequeño) y San Salvador (donde se mantuvo la tendencia aunque sin alcanzar la significación estadística) (cuadro 3). 
CUADRO 4. Violencia sufrida y ejercida, en función del sexo. Estudio Multicéntrico sobre Actitudes y Normas Culturales frente a la Violencia (ACTIVA), 1997

\begin{tabular}{|c|c|c|c|c|c|c|}
\hline & $\begin{array}{l}\text { Varones que dicen } \\
\text { ejercer violencia }\end{array}$ & & $\begin{array}{l}\text { Mujeres que dicen } \\
\text { sufrir violencia }\end{array}$ & $\begin{array}{l}\text { Mujeres que dicen } \\
\text { ejercer violencia }\end{array}$ & & $\begin{array}{l}\text { Varones que dicen } \\
\text { sufrir violencia }\end{array}$ \\
\hline \multicolumn{7}{|l|}{ Grito } \\
\hline \multicolumn{7}{|l|}{ Bofetada } \\
\hline & 5,2 & $<$ & 5,9 & 5,7 & $>$ & 4,7 \\
\hline & 2,7 & $<$ & 2,8 & 3,1 & $>$ & 2,4 \\
\hline Media $^{a}$ & 3,0 & $<$ & 4,0 & 3,7 & $>$ & 2,7 \\
\hline
\end{tabular}

a Media: Frecuencia media anual (número de veces) con la que ejercen esta conducta las personas que alguna vez la han mostrado.

CUADRO 5. Sexo, desempleo y violencia recibida de la pareja. Estudio Multicéntrico sobre Actitudes y Normas Culturales frente a la Violencia (ACTIVA), 1997

\begin{tabular}{|c|c|c|c|c|c|c|c|c|}
\hline Sexo & \multicolumn{2}{|c|}{ Le gritaron } & \multicolumn{2}{|c|}{ Le abofetearon } & \multicolumn{2}{|c|}{ Le golpearon } & \multicolumn{2}{|c|}{ Violencia recibida } \\
\hline Trabaja & 58,8 & 5,8 & 7,3 & 2,7 & 2,7 & 4,6 & 58,8 & 13,5 \\
\hline No trabaja & 43,7 & 4,5 & 2,7 & 2,4 & 1,1 & 2,1 & 44,9 & 6,8 \\
\hline \multicolumn{9}{|l|}{ Mujer } \\
\hline
\end{tabular}

a Media: frecuencia media anual (número de veces) con la que ejercen esta conducta las personas que alguna vez la han mostrado.

b Frecuencia ponderada (Sí): entre las personas que han ejercido violencia, es el resultado de sumar la frecuencia anual de los tres actos de violencia y multiplicar cada uno de ellos por un índice que refleje su gravedad (el valor inverso de su frecuencia de aparición en la muestra). El peso de cada acto de violencia es: grito $=1$, bofetada $=10$ y golpe $=20$.

Las mujeres afirmaron ejercer más violencia contra sus parejas que los varones (cuadro 3). Las diferencias detectadas solo fueron estadísticamente significativas en el caso de los gritos $(P<$ 0,001 ), en el sentido de que en todas las ciudades las mujeres dijeron gritar más que los hombres. Ahora bien, al analizar la violencia que dijeron sufrir varones y mujeres, también fueron estas últimas las que notificaron sufrir más violencia. Un análisis más detallado reveló que siempre fue menor la violencia que dijeron ejercer los hombres que la que las mujeres dijeron sufrir, y viceversa (siempre fue mayor la violencia que las mujeres dijeron ejercer que la que los varones dijeron sufrir). Esta tendencia se observó en todas las ciudades excepto en Madrid y San José, donde la frecuencia de bofetadas que las mujeres dijeron dar fue menor que la que los hombres dijeron recibir, y en Cali donde, por el contrario, fue mayor el porcentaje de varones que dijeron dar golpes con objetos que el de mujeres que dijeron haberlos recibido (cuadro 4).

Los jóvenes dijeron ejercer más violencia contra sus parejas (cuadro 3). Esta tendencia se observó, con escasas excepciones, en todas las ciudades. El dato más relevante de diferenciación entre ciudades se recabó en Cali y Madrid: en estas ciudades los valores extremos se mantuvieron en el orden general (los que más ejercen la violencia son los de 18 a 30 años y los que menos la ejercen, los de 57 a 70), aunque las generaciones intermedias (31-43 y
44-56 años) intercambiaron el orden, esto es, los de 31 a 43 años ejercieron menos violencia.

Al ser el nivel académico una variable muy relacionada con el nivel socioeconómico, las personas con estudios universitarios respondieron en consonancia con las de mayor nivel económico, e indicaron ejercer menos violencia contra sus parejas que las que carecían de estudios o tenían la primaria incompleta. Ahora bien, al eliminar la influencia del nivel socioeconómico, no se observó una ordenación lógica significativa ni se mantuvieron estas diferencias; es decir, las personas de clase alta sin estudios no dijeron ejercer más violencia que los universitarios de esta misma condición económica. Lo mismo sucedió con 
CUADRO 6. Actitudes justificadoras e inhibidores y facilitadores de la agresión versus violencia ejercida. Estudio Multicéntrico sobre Actitudes y Normas Culturales frente a la Violencia (ACTIVA), 1997

\begin{tabular}{|c|c|c|c|c|c|c|c|c|c|}
\hline & \multicolumn{2}{|c|}{ Gritó } & \multicolumn{2}{|c|}{ Dio bofetada } & \multicolumn{2}{|c|}{ Dio golpe } & \multicolumn{3}{|c|}{ Violencia ejercida (global) } \\
\hline Actitudes & & & & & & & & & \\
\hline $\begin{array}{l}\text { Justifica violencia en la } \\
\text { Desacuerdo } \\
\text { No seguro } \\
\text { Acuerdo }\end{array}$ & $\begin{array}{l}58,1 \\
72,9 \\
72,5\end{array}$ & $\begin{array}{l}4,5 \\
5,6 \\
5,5\end{array}$ & $\begin{array}{r}4,6 \\
11,0 \\
14,6\end{array}$ & $\begin{array}{l}3,2 \\
3,9 \\
2,9\end{array}$ & $\begin{array}{r}2,3 \\
11,5 \\
6,5\end{array}$ & $\begin{array}{l}3,3 \\
3,6 \\
3,6\end{array}$ & $\begin{array}{l}58,6 \\
74,4 \\
74,4\end{array}$ & $\begin{array}{r}9,5 \\
22,3 \\
17,3\end{array}$ & $\begin{array}{r}5,6 \\
16,6 \\
12,9\end{array}$ \\
\hline $\begin{array}{l}\text { Intolerancia } \\
\text { Baja } \\
\text { No seguro } \\
\text { Alta }\end{array}$ & $\begin{array}{l}59,1 \\
62,3 \\
62,0\end{array}$ & $\begin{array}{l}4,6 \\
4,4 \\
5,2\end{array}$ & $\begin{array}{l}5,0 \\
6,6 \\
8,9\end{array}$ & $\begin{array}{l}3,2 \\
3,0 \\
3,2\end{array}$ & $\begin{array}{l}2,6 \\
3,2 \\
5,9\end{array}$ & $\begin{array}{l}3,4 \\
3,2 \\
3,7\end{array}$ & $\begin{array}{l}59,5 \\
63,3 \\
63,7\end{array}$ & $\begin{array}{l}10,3 \\
10,8 \\
16,4\end{array}$ & $\begin{array}{r}6,1 \\
6,8 \\
10,5\end{array}$ \\
\hline Inhibidores & & & & & & & & & \\
\hline Facilitadores & & & & & & & & & \\
\hline $\begin{array}{l}\text { Embriaguez } \\
\text { Nunca } \\
1-4 \text { veces mes } \\
50+\text { veces mes }\end{array}$ & $\begin{array}{l}56,1 \\
68,0 \\
69,3\end{array}$ & $\begin{array}{l}4,5 \\
4,7 \\
5,8\end{array}$ & $\begin{array}{r}4,5 \\
7,2 \\
12,7\end{array}$ & $\begin{array}{l}3,2 \\
3,2 \\
2,9\end{array}$ & $\begin{array}{l}2,5 \\
3,8 \\
4,4\end{array}$ & $\begin{array}{l}3,7 \\
2,8 \\
4,1\end{array}$ & $\begin{array}{l}56,7 \\
68,7 \\
70,1\end{array}$ & $\begin{array}{l}10,3 \\
11,2 \\
16,2\end{array}$ & $\begin{array}{r}5,8 \\
7,7 \\
11,4\end{array}$ \\
\hline $\begin{array}{l}\text { Castigo corporal } \\
\text { Nunca } \\
\text { Casi nunca } \\
\text { 1-4 veces mes } \\
\text { Casi diario }\end{array}$ & $\begin{array}{l}49,7 \\
59,4 \\
67,3 \\
64,7\end{array}$ & $\begin{array}{l}4,4 \\
4,3 \\
4,9 \\
5,5\end{array}$ & $\begin{array}{l}2,7 \\
5,5 \\
6,7 \\
7,8\end{array}$ & $\begin{array}{l}3,0 \\
3,0 \\
4,1 \\
3,2\end{array}$ & $\begin{array}{l}1,3 \\
2,9 \\
3,3 \\
5,0\end{array}$ & $\begin{array}{l}4,7 \\
3,4 \\
2,5 \\
3,8\end{array}$ & $\begin{array}{l}50,2 \\
60,1 \\
67,7 \\
65,5\end{array}$ & $\begin{array}{r}8,4 \\
10,3 \\
10,1 \\
16,2\end{array}$ & $\begin{array}{r}4,2 \\
6,2 \\
6,8 \\
10,6\end{array}$ \\
\hline $\begin{array}{l}\text { Armas } \\
\text { No tiene ni desea } \\
\text { No tiene pero desea } \\
\text { Sí tiene }\end{array}$ & $\begin{array}{l}57,7 \\
67,4 \\
58,1\end{array}$ & $\begin{array}{l}4,5 \\
5,0 \\
4,5\end{array}$ & $\begin{array}{l}4,5 \\
9,3 \\
4,7\end{array}$ & $\begin{array}{l}3,0 \\
3,5 \\
3,2\end{array}$ & $\begin{array}{l}2,5 \\
4,9 \\
2,0\end{array}$ & $\begin{array}{l}3,1 \\
3,9 \\
3,3\end{array}$ & $\begin{array}{l}58,3 \\
68,0 \\
58,9\end{array}$ & $\begin{array}{r}9,5 \\
15,5 \\
9,2\end{array}$ & $\begin{array}{r}5,5 \\
10,5 \\
5,4\end{array}$ \\
\hline
\end{tabular}

${ }^{a}$ Media: frecuencia media anual (número de veces) con la que ejercen esta conducta las personas que alguna vez la han mostrado.

${ }^{\text {b }}$ Frecuencia ponderada (Sí): entre las personas que han ejercido violencia, es el resultado de sumar la frecuencia anual de los tres actos de violencia y multiplicar cada uno de ellos por un índice que refleje su gravedad (el valor inverso de su frecuencia de aparición en la muestra). El peso de cada acto de violencia es: grito $=1$, bofetada $=10$ y golpe $=20$.

${ }^{c}$ Frecuencia ponderada (total): lo mismo que en el caso anterior, haciendo el cálculo sobre todas las personas (hayan ejercido o no la violencia).

las de nivel económico medio y bajo. No se encontraron diferencias significativas en el nivel de violencia ejercida o sufrida debidas a la diferencia de edad o al nivel académico entre los miembros de la pareja.

No se observaron diferencias en el nivel de violencia ejercida y recibida en función de la situación laboral (activo o desempleado). Sin embargo, al diferenciar por sexo sí hubo diferencias. Los hombres que trabajaban dijeron recibir más violencia de sus parejas que los que estaban sin trabajo $y$, en cambio, las mujeres que trabajaban afirmaron sufrir menos violencia que las que no lo hacían. En los varones estas diferencias fueron estadística- mente significativas en cuanto a los gritos recibidos $(P=0,018)$ y a la escala acumulada $(P=0,046)$, y en las mujeres respecto a las bofetadas recibidas $(P<0,0001)$ y a la escala acumulada $(P<0,0001)$ (cuadro 5).

Al categorizar a los integrantes de la muestra según su estado civil, en todos los tipos de violencia la tendencia fue la misma: las personas no casadas (unión libre, solteros, separadosdivorciados y viudos) dijeron ejercer más violencia que las casadas (cuadro 3), y las diferencias registradas fueron estadísticamente significativas. Esta tendencia se mantuvo en todas las ciudades (solo en Santiago la frecuencia con que los casados golpearon a su pa- reja fue mayor que la de los solteros, si bien no alcanzó significación estadística). Al analizar detalladamente al grupo de los que no estaban casados, se observó que el comportamiento de los separados-divorciados y viudos que vivían con una nueva pareja fue idéntico al de los casados, siendo las personas que definieron su estado civil como soltero/a o unión libre los que dijeron ejercer más violencia.

En todas las ciudades, quienes tenían o cuidaban niños afirmaron gritar más a sus parejas que quienes no tenían niños a su cargo $(P<0,0001)$, pero no se observaron diferencias en las formas de violencia física (abofetear y golpear con objeto) (cuadro 3). 
Se hicieron varias tipologías de estructura familiar en función de distintos criterios y no se encontraron diferencias significativas en el nivel de violencia ejercida o sufrida en la pareja, salvo las mencionadas (estado civil y existencia de hijos). La presencia de otros familiares diferentes de los cónyuges e hijos, y las diversas formas de convivencia familiar que se pueden generar al combinar los distintos tipos de parientes y no parientes, no afectaron al nivel de violencia que los entrevistados dijeron ejercer y sufrir.

Las ciudades donde más se justificó la violencia conyugal fueron Cali y Caracas, donde se registró, respectivamente, que 16,8 y $14,4 \%$ de las personas estaban de acuerdo (o manifestaron duda) con que en ocasiones está justificado pegarle a la pareja. En el extremo de menor justificación se encontraron Madrid y San José, donde los porcentajes ascendieron a 6 y $6,3 \%$, respectivamente. En todas las ciudades, los hombres justificaron más los dos tipos de violencia (esposa a esposo y de este a aquella) que las mujeres.

Como puede observarse en el cuadro 6, las personas que justificaron que en ocasiones era lícito dar una cachetada a la esposa o esposo, ejercieron más violencia sobre la pareja que aquellas que consideraban lo contrario. En la muestra general las diferencias fueron estadísticamente significativas para los tres tipos de violencia $(P<0,0001)$. En todas las ciudades se constató la misma tendencia (a mayor justificación, mayor violencia), aunque hubo diferencias en el caso de los indecisos (los que contestaron "no estoy seguro"). En Salvador de Bahía y Rio de Janeiro los indecisos se situaron en el nivel intermedio de violencia; en las demás ciudades fueron los que ejercieron más violencia.

Los que estaban más de acuerdo en que los vecindarios tienen que ser homogéneos (en cuanto a clase social, religión, raza o ideas políticas), es decir, los que se han definido como más intolerantes, ejercieron más violencia contra la pareja que los más tolerantes (cuadro 6). Aunque en el conjunto de la muestra las diferencias fueron significativas en los tres tipos de violencia (gritos: $P=$
0,0277; bofetadas: $P=0,00218$, y golpes: $P=0,0076)$, en las ciudades, a pesar de seguir la misma tendencia, no se encontraron diferencias estadísticamente significativas debido a la desproporción entre los grupos comparados (con muchos menos ciudadanos que estaban de acuerdo en que los vecindarios deben ser completamente homogéneos que aquellos que discrepaban).

Las personas que se consideraron hábiles para controlarse y explicarse ante los problemas fueron las que dijeron ejercer menor violencia contra su pareja (cuadro 6), y en la muestra global estas diferencias fueron estadísticamente significativas para los tres tipos de violencia $(P<0,0001)$. En todas las ciudades los resultados siguieron la misma tendencia.

En la muestra global, las personas que habían recibido golpes en su casa durante su infancia fueron las que con más frecuencia dijeron ejercer más violencia contra su pareja. Estas diferencias fueron estadísticamente significativas en los tres tipos de violencia $(P<$ $0,0001)$, y en todas las ciudades se registró la misma tendencia. Los que dijeron beber alcohol en exceso fueron los que afirmaron gritar y abofetear más a sus parejas $(P<0,0001)$. No se observaron diferencias significativas entre los que poseían armas y los que no las poseían, aunque sí entre los que deseaban tenerlas y los que no las querían. Los que deseaban tener armas fueron los que más ejercieron la violencia en sus tres modalidades $(P<$ 0,0001) (cuadro 6).

\section{DISCUSIÓN}

La estructuración de los múltiples elementos relacionados con la violencia conyugal en un modelo explicativo organizado por bloques de variables puede ser útil para actuar sobre las causas del maltrato. La forma como se articuló el modelo que se presenta en este artículo no excluye algunas variaciones, especialmente entre los factores considerados de identificación personal y los facilitadores. Por ejemplo, si se le quisiera dar un carácter más psicológico al modelo, la experiencia de malos tratos en la infancia podría considerarse elemento identificador y la clase social, elemento facilitador o inhibidor de la agresión. Existen muchos elementos que no se han tenido en cuenta a pesar de que tienen una importancia vital en el proceso, como los trastornos psicopatológicos y otras características psicológicas (atribuciones, percepciones, reacciones emocionales, historia particular de aprendizajes, etc.) y biológicas relacionadas directamente con el maltrato. No obstante, estos elementos eran inabarcables en un estudio como este.

Tras analizar los resultados y verificar las asociaciones entre las variables propuestas, se observa que los datos corroboran la utilidad del modelo propuesto. $\mathrm{Al}$ estudiar las asociaciones se confirma el origen multicausal de la violencia en la pareja. La ventaja que supone la agrupación conceptual de todos estos factores es que pueden ayudar a abordar programas específicos para prevenir el maltrato, que estén centrados en el ámbito educativo y de la socialización (prevención de los malos tratos a la infancia); en el fortalecimiento de actitudes contrarias a la justificación de la violencia; en el aprendizaje de técnicas y habilidades de gestión de conflictos por procedimientos no violentos, o en la facilitación de oportunidades socioeconómicas para reducir el desequilibrio de poder en las parejas y las carencias de medios económicos en las familias. Ninguna de las variables analizadas explica por sí sola la aparición de la violencia conyugal, pero es predecible que la incidencia en cada una de ellas contribuirá a reducir el maltrato en la pareja.

A pesar de las afirmaciones que se presentan en los resultados, la forma como se ha abordado la violencia en la pareja a partir de las respuestas de uno de los miembros de la misma, referidas a lo que recuerda de los últimos 12 meses, es claramente insuficiente. En este sentido, al tener en cuenta únicamente a las personas que viven con su pareja, no se han analizado los casos de parejas cuya separación no fue amistosa, en las cuales la violencia se manifiesta más intensamente, sobre todo la de los hombres hacia las muje- 
res $(1,3)$. Sería preciso tener en cuenta la dinámica de la interacción de la pareja y profundizar en muchos elementos, como los actitudinales y emocionales, que no se han abordado en el presente estudio, pues se pretendía dar una visión global de las distintas formas de violencia (conyugal, hacia los hijos, hacia los no familiares, violencia política, etc.) y era preciso limitar al máximo el número de preguntas. No obstante, la riqueza de los resultados es evidente y las posibilidades de interpretación y de investigaciones complementarias que quedan abiertas son múltiples.

De cara a los programas de intervención (económica, social, policial, sanitaria, etc.) que ponen en marcha las distintas autoridades, conviene tener en cuenta que en determinadas circunstancias (las analizadas en este estudio) es más probable que le agredan a uno en el hogar que fuera de él. En la muestra total del proyecto ACTIVA, el porcentaje de personas que afirmaron haber sido golpeadas por no familiares fue de $4,6 \%$ y el de las que dijeron haber recibido este trato de la policía, 2,3\%. Frente a estos datos ajenos al hogar, $5,4 \%$ de las personas manifestaron haber recibido bofetadas de su pareja.

No se observó un comportamiento paralelo entre el nivel de violencia general de la ciudad (el delictivo) y el vivido en la pareja. Las ciudades donde el nivel de violencia fuera del hogar fue significativamente más frecuente que en el resto - Caracas y, sobre todo, San Salvador- no son los lugares donde se produce más violencia conyugal. Algo similar, pero a la inversa, se observó con Santiago de Chile, que, siendo la ciudad donde menos violencia se registró en la calle, ocupó un lugar intermedio en cuanto a la intensidad de la violencia conyugal ejercida, solo superada por San Salvador, Cali y Salvador de Bahía. San José y Madrid fueron las ciudades donde se registraron niveles relativamente bajos de violencia conyugal y delictiva.

Es importante destacar los resultados relacionados con las diferencias entre hombres y mujeres a la hora de ejercer y ser víctima de la violencia en el hogar. En el caso de los gritos, las mujeres superan claramente a los varones, pero aunque en las otras formas de violencia (bofetadas y golpes con objetos) las mujeres aparentemente ejercen más violencia (elemento contrario a la hipótesis más admitida socialmente), el nivel de agresión es similar, ya que las mujeres perciben un nivel mayor de violencia (tanto ejercida como recibida) que los varones. Esta es una pauta cultural de primer orden en los países estudiados, donde las mujeres dan más importancia a lo que sucede en el hogar que los hombres. La imagen de la mujer que le insiste al esposo para que converse o le llama la atención (dentro o fuera del hogar) sobre las dificultades conyugales, suele contrastar con la del varón, que resta importancia a las situaciones conflictivas (59).

La constatación de que las mujeres no adoptan una actitud pasiva ante la violencia de sus compañeros confirma que la violencia en la pareja debe abordarse teniendo en cuenta a los dos protagonistas de la relación, como sugieren Strauss y Gelles (7) y Perrone y Nannini (27). Esto no debe suponer el olvido de un hecho patente: aunque la violencia sea recíproca, el proceso suele darse en una situación en que habitualmente existe un diferencial de poder a favor del hombre. Por las relaciones desiguales que se han observado en las relaciones de pareja, el varón es el que suele controlar la autonomía de la mujer por medio de su aportación económica, apoyado en muchas ocasiones por instituciones públicas dominadas básicamente por hombres que no siempre tratan adecuadamente a las mujeres que se acercan en demanda de ayuda o de justicia (3). Cualquier elemento que equilibre el poder dentro de la pareja, como el trabajo de la mujer fuera del hogar o la mejora de su fuerza física, pueden ejercer un efecto a la hora de equilibrar las consecuencias de los actos de violencia bidireccional. Tampoco debe olvidarse que este estudio se ha llevado a cabo con personas que actualmente viven en pareja, lo cual deja de lado al sector donde se producen actos más extremos de violencia, como la tortura psicológica de utilizar a los hijos para dañar al cónyuge (más habitual en mujeres) y el acoso sexual y la violencia física con la excompañera que pretende establecer nuevas relaciones (conducta más habitual en hombres).

Las mujeres que trabajan reciben menos violencia de sus compañeros, lo cual sugiere que es importante aumentar su autonomía económica respecto a los hombres, no solo por lo que puede suponer de independencia económica. La relación habitual y continuada con personas ajenas al núcleo familiar es un factor inhibidor de la violencia en el hogar y modifica creencias y actitudes favorecedoras del maltrato (24).

Los jóvenes ejercen más la violencia, del mismo modo que tienen una conducta más activa que las personas mayores en todos los órdenes. Esta clara influencia de la edad en los malos tratos en la pareja ha sido explicada de muy diversas formas: mayor excitabilidad, mayor intensidad emocional de las relaciones, mayores factores de estrés, como las dificultades en la crianza de los hijos y otros (60). Puesto que en otros estudios $(2,43)$ se ha comprobado que los malos tratos se dan en los primeros años de una relación, conviene reforzar la idea de que no hay que disculpar el primer acto de violencia, ya que esa actitud puede favorecer que esta se torne crónica.

El que no se hayan encontrado diferencias significativas en cuanto a la estructura familiar (en función de las diferentes configuraciones de las relaciones entre los parientes y no parientes), ni con respecto al desequilibrio de edad o nivel académico, es un elemento positivo, ya que parece que el modelo de familia nuclear tradicional está empezando a perder la hegemonía de que gozaba hasta hace unas décadas, abriéndose paso nuevas formas de convivencia. Ahora bien, otro de los resultados relacionados con la familia indica que un compromiso público (como el matrimonio) parece menos ligado a la conducta violenta que la convivencia sin estar casados (19).

En el camino de la reducción de la agresión conyugal es de gran importancia que los ciudadanos, especialmente las mujeres, adopten actitudes contrarias a la justificación de la vio- 
lencia. En las ciudades donde es alta la proporción de varones y mujeres que consideran justificado que se golpee a la mujer de vez en cuando (como Cali), los primeros afirman ejercer más violencia que la que ellas dicen recibir, lo contrario de lo que se observa en ciudades donde el nivel de violencia es menor, como San José y Madrid, y donde la justificación de estas conductas es menor en general y las mujeres las justifican menos que los varones. En este mismo sentido, cualquier modificación de las actitudes de justificación de la violencia y de la intolerancia social, en la línea de censurar la agresión y aumentar el respeto por las diferencias, podría tener un efecto inhibidor de la conducta violenta (30).

Se considera importante confirmar la hipótesis del proceso circular de la violencia o de su transmisión generacional. Esta confirmación en un estudio internacional puede aportar nuevos argumentos a los educadores que alertan sobre la importancia de una socialización no violenta de los menores en sus hogares y fuera de ellos. Otros facilitadores de la agresión, como el consumo de alcohol, deberían hacernos reflexionar sobre los procesos de introducción de niños y adolescentes en la cultura del alcohol. También conviene destacar que se confirma nuevamente la relación directa entre la presencia (real o deseada) de armas y la agresión, hecho que suele aparecer en la mayor parte de las investigaciones realizadas desde el estudio pionero de Berkowitz y LePage (61). En la presente investigación, el caso más favorable fue siempre el de aquellos que no poseen armas y no desean poseerlas.

La constatación de asociaciones entre las variables estudiadas en esta investigación y la violencia conyugal abre nuevas vías de actuación desde distintos campos (salud pública, terapia de pareja, acción legal, promoción del cambio de actitudes, etc.). Estas deben orientarse inexorablemente a reforzar los elementos inhibidores (dotación de habilidades para enfrentarse a los conflictos, reducción del estrés, etc.) y a reducir el impacto de los facilitadores promoviendo programas y actuaciones no estereotipados que se basen en posibilidades reales de actuación con personas víctimas de la violencia, pero que, sobre todo, incidan en los elementos estructurales que soportan el amargo edificio del maltrato.

Agradecimiento. Este artículo se basa en los datos del Estudio Multicéntrico sobre Actitudes y Normas Culturales sobre la Violencia (proyecto ACTIVA), que fue realizado en ocho ciudades de América Latina y España bajo los auspicios y la coordinación de la Organización Panamericana de la Salud.

\section{REFERENCIAS}

1. Instituto de la Mujer. Violencia contra la mujer. Madrid: Ministerio del Interior; 1991.

2. Sarasúa B, Zubizarreta I, Echeburúa E, Corral P. Perfil psicológico del maltratador a la mujer en el hogar. En: Echeburúa E, ed. Personalidades violentas. Madrid: Pirámide; 1994. pp. 111-126.

3. Ferreira GB. Hombres violentos. Mujeres maltratadas. Buenos Aires: Editorial Sudamericana; 1995.

4. Torres P, Espada FJ. Violencia en casa. Madrid: Aguilar; 1996.

5. Zubizarreta I, Sarasúa B, Echeburúa E, Corral P, Sauca P, Emparanza I. Consecuencias psicológicas del maltrato doméstico. En: Echeburúa E, ed. Personalidades violentas. Madrid: Pirámide; 1994. pp. 129-146.

6. Straus MA, Gelles RJ, Steinmetz S. Behind closed doors: violence in the American family. New York: Anchor/Doubleday; 1980.

7. Straus MA, Gelles RJ. Physical violence in American families: risk factors and adaptations to violence in 8145 families. New Brunswich, NJ: Transaction;1990.

8. Levinson D. Family violence in cross-cultural perspective. Newbury Park, CA: Sage; 1989.

9. Gelles $R$, Cornell $C$, eds. International perspectives on family violence. Lexington, MA: D.C. Health; 1983.

10. Heise LL. La violencia contra la mujer. Organización global para el cambio. En: Edelson J, Eisikovits Z. Violencia doméstica: la mujer York: UNIFEM; 1992. golpeada y la familia. Buenos Aires: Granica 1997. pp. 19-58.

11. Heise L, Chapman JR. Reflections on a movement: the U.S. battle against women abuse. En: Schuler M. Freedom from violence. New York: UNIFEM; 1992. pp. 257-294.

12. Schuler M. Freedom from violence. New

13. Basu A. Alternative forms of organizing women in India: the challenge of difference in the Indian Women's Movement. Barnard Occas Pap Wom Issues 1987; 2:39-61.

14. Carrillo R. Battered dreams: violence against women as an obstacle to development. Nueva York: Fondo para el Desarrollo de la Mujer de las Naciones Unidas; 1992.

15. Gelles RJ, Straus M.A. The medical and psychological cost of family violence. En: Straus MA, Gelles MJ. Physical violence in American families: risk factors and adaptations to violence in 8145 families. New Brunswick, NJ: Transaction; 1990.

16. World Bank. World development report 1993: Investing in health. New York: Oxford University Press; 1993.

17. Hotaling GT, Sugarman DB. An analysis of risk markers in husband to wife violence: the current state of knowledge. Violence Vic 1986;1:101-124.

18. Baron RA, Richardson DR. Human agression. New York: Plenun; 1994
19. Berkowitz L. Aggression: its causes, consequences and control. New York: McGrawHill, Inc.; 1993.

20. Moreno F. Explicaciones de la violencia: vías ciegas para la intervención. Energ Carac Soc 1996;20:165-178.

21. Dutton DG, Golant SK. The Batterer. A Psychological Profile. New York: Basic Books; 1995.

22. Montoya O. Nadando contra corriente. Managua: Puntos de encuentro; 1998.

23. Stith SM, Williams MB, Rosen K. Psicosociología de la violencia en el hogar: estudio, consecuencias. Bilbao: Desclée de Brouwer; 1992.

24. Ravazzola MC. Historias infames: los maltratos en las relaciones. Buenos Aires: Paidós; 1997.

25. Edelson J, Eisikovits ZC. Violencia doméstica: la mujer golpeada y la familia. Buenos Aires: Granica; 1997.

26. Kanuha V. Violencia doméstica, racismo y el movimiento de mujeres golpeadas en Estados Unidos. En: Edelson J, Eisikovits Z. Violencia doméstica: la mujer golpeada y la familia. Buenos Aires: Granica; 1997. pp. 59-82.

27. Perrone R, Nannini M. Violencia y abusos sexuales en la familia: un abordaje sistémico y comunicacional. Buenos Aires: Paidós; 1997.

28. Bandura A. Aggression: a social learning analysis. Englewood Cliffs, N.J.: Prentice Hall; 1973. 
29. Bandura A. Social learning theory analysis. Englewood Cliffs, N.J.: Prentice Hall; 1977.

30. Moreno F. Infancia y guerra en Centroamérica. San José: Editorial FLACSO; 1991.

31. Moreno F. Identidad y violencia política. En: Younis JA. Cultura, psicología y problemas sociales. Las Palmas: Nogal Ediciones; 1995: 151-163.

32. Kadushin A, Martin JA. Child abuse. An interactional event. New York: Basic Books; 1981.

33. Wolfe DA. Child-abusive parents: an empirical review and analysis. Psychol Bull 1985; 97:462-482.

34. Howell MJ, Pugliesi KL. Husbands who harm: predicting spousal violence by men. J Fam Violence 1988;3:15-27.

35. Dollard J, Doob L, Miller N, Mowrer OH, Sears R. Frustration and aggression. New Haven, Conn.: Yale University Press; 1939.

36. Berkowitz L. Whatever happened to the frustration-aggression hypothesis? Am Behav Sci 1978; 21:691-708.

37. Martín-Baró I. Acción e ideología. Psicología social desde Centroamérica. San Salvador: UCA Editores; 1983.

38. Echeburúa E, Corral P, Sarasúa B, Zubizarreta I, Sauca D. Malos tratos y agresiones sexuales: lo que la mujer debe saber y puede hacer. Vitoria: Servicio de Publicaciones de Emakunde/Instituto Vasco de la Mujer; 1990.

39. Straus MA, Gelles RJ. Societal change and change in family violence from 1975 to 1985 as revealed by two national survey. J Marr Fam 1986;48:465-479.
40. McNeely RL, Robinson-Simpson G. The truth about domestic violence: a falsely framed issue. Soc Work 1987:485-490.

41. Walker L. The battered woman. New York: Harper and Row; 1979.

42. Bolton F. The pregnant adolescent. Newbury Park, CA: Sage Publications; 1981.

43. O’Leary KD, Barling J, Arias I, Rosenbaum A, Malone J, Tyree A. Prevalence and stability of physical agression between spouses: a longitudinal analysis. J Consult Clin Psychol 1989;57:263-268.

44. Burr WR, Hill R, Nye FI, Reiss IL, eds. Contemporary theories about the family. New York: The Free Press; 1979.

45. Willi J. La pareja humana: relación y conflicto. Madrid: Morata; 1985.

46. Rubin J, Rubin C. Cuando las familias se pelean: cómo resolver conflictos. Barcelona: Paidós Ibérica; 1990.

47. Little LF. Terapia Gestalt con mujeres víctimas de la violencia en la intimidad. En: Stith SM, Williams MB, Rosen K. Psicosociología de la violencia en el hogar: estudio, consecuencias. Bilbao: Desclée de Brouwer; 1992. pp. 73-90.

48. Tolman RM. Las sanciones que se aplican a los golpeadores. ¿Qué hacer además de encarcelar y asesorar? En: Edelson J, Eisikovits Z. Violencia doméstica: la mujer golpeada y la familia. Buenos Aires: Granica; 1997 pp. 245-266.

49. Pressman B. Wife-abused couples: the need for comprehensive theoretical perspectives and integrated treatment models. J Feminist Fam Ther 1989;1:23-43.

50. Shamai M. Terapia de pareja con mujeres golpeadas y hombres agresores. ¿Tiene algún futuro? En: Edelson J, Eisikovits Z Violencia doméstica: la mujer golpeada y la familia. Buenos Aires: Granica; 1997: 289-310.

51. Herzberger SD. Violence within the family. Social psychological perspectives. Boulder Co: Westview Press; 1996.

52. Moreno F. La polarización, el pretendido mal. Interac Soc 1993;3:117-132

53. McCubbin $\mathrm{H}$, Figley C. Stress and the family. Vol 1. Coping with normative transitions. New York: Bruner/Mazel; 1983.

54. Zaidi LY, Knutson JF, Mehm JG. Transgenerational patterns of abusive parenting: Ana$\log$ and clinical tests. Aggressive Behav 1989;15:137-152.

55. Rosembaum A, O'Learly K. Marital violence: characteristics of abusive couples. J Consult Clin Psycol 1981;49:63-71.

56. Coleman K, Weinman M, Hsi B. Factors affecting conjugal violence. J Psychol 1980 105:197-202.

57. Myers D. Social psychology. New York: McGraw Hill Inc.; 1993

58. Fournier M, de los Ríos R, Orpinas P, PiquetCarneiro P. Estudio Multicéntrico sobre Actitudes y Normas Culturales frente a la Violencia. Proyecto ACTIVA: metodología. Rev Panam Salud Publica 1999;5(4/5):223-232

59. Roma J. Ellos hablan. Barcelona: Plaza y Janés; 1998.

60. Fernández C. Jóvenes violentos. Barcelona: Icaría; 1998.

61. Berkowitz L, LaPage A. Weapons as aggression eliciting stimuli. J Pers Soc Psychol 1967; 7:202-207.
ABSTRACT

Violence in couples
This article describes variables related to different forms of violence in couples. These variables have been organized in a theoretical model that takes into account cultural factors, sociodemographic and family characteristics, attitudes, and other variables defined as inhibitors and facilitators of violence in conflict situations. For the ACTIVA project, a representative sample consisting of 10821 people was interviewed in eight cities. For this research on couples, 6184 of those responses were taken into consideration, from persons who were in a marriage or an unmarried relationship during the year before the interview. The data were obtained from verbal responses to a questionnaire completed in the interviewees' residences. The variables that were clearly associated with couples violence were: socioeconomic level (the fewer the economic resources, the greater the violence), gender (women reported both using and receiving more violence than men did, although the actual level of violence was similar), age (there was more violence between younger people), marital status (there was more violence between unmarried persons), childhood abuse (those most abused in childhood), excessive alcohol consumption (those who have gotten drunk), holding attitudes justifying violence, and having fewer skills to deal with conflicts. Acts of violence, which both men and women commit in relationships, originate in the socialization process, both through the practice of abuse as well as the transmission of values that lead to attitudes justifying violence. A number of things could help markedly reduce the levels of couples violence, including a balance of power between the two persons in the relationship, a modification of attitudes, an improvement in conflictresolution skills, and a reduction in stress-producing factors. 